\title{
PRODUTIVIDADE DE CANA-DE-AÇÚCAR SOB ADUBAÇÃO COM TORTA DE FILTRO ENRIQUECIDA COM FOSFATO SOLÚVEL ${ }^{1}$
}

\author{
Diego Henriques Santos ${ }^{2}$, Carlos Sérgio Tiritan ${ }^{3}$, José Salvador Simoneti Foloni ${ }^{4}$, Luciana Boulhosa Fabris ${ }^{3}$
}

\section{ABSTRACT \\ SUGARCANE YIELD UNDER FERTILIZATION WITH FILTER CAKE ENRICHED WITH SOLUBLE PHOSPHATE}

Phosphorus is considered an essential element for plants and it is found in small amounts in Brazilian soils. The filter cake residue, composed of a mixture of bagasse and decanting sludge, has high levels of organic matter, phosphorus and calcium. The phosphorus present in the filter cake is organic, and its release, as it happens to the nitrogen, occurs gradually by mineralization and by microorganisms attack in the soil. This study aimed to evaluate sugarcane vegetative growth and yield under fertilization with filter cake enriched with soluble phosphate. The experiment was carried out in Presidente Prudente, São Paulo State, Brazil, by using a randomized complete block design, in a $5 \times 4$ factorial scheme, where the first factor consisted of filter cake doses $\left(0 \mathrm{t} \mathrm{ha}^{-1}, 0.5 \mathrm{t} \mathrm{ha}^{-1}\right.$, $1.0 \mathrm{tha}^{-1}, 2.0 \mathrm{tha}^{-1}$, and $\left.4.0 \mathrm{tha}^{-1}\right)$ and the second of phosphorus fertilizer doses $\left(0 \mathrm{~kg} \mathrm{ha}^{-1}, 50 \mathrm{~kg} \mathrm{ha}^{-1}, 100 \mathrm{~kg} \mathrm{ha}^{-1}\right.$, and $200 \mathrm{~kg} \mathrm{ha}^{-1}$ of $\mathrm{P}_{2} \mathrm{O}_{5}$ ), with 4 repetitions, totalizing 80 plots. The experiment evaluated the tiller number, at 30,60, 90, and 120 days after planting, ${ }^{\circ}$ Brix, and yield. The stalk yield and tillering were influenced by the filter cake rates applied to the soil. Filter cake doses and their combination with phosphate did not change the juice quality (Brix) at harvest.

KEY-WORDS: Saccharum spp.; organo-mineral fertilizers; triple superphosphate.

\section{INTRODUÇÃO}

O fósforo (P) é um importante macronutriente, componente estrutural de macromoléculas, como ácidos nucléicos e fosfolipídeos, e, também, da adenosina trifosfato (ATP). É considerado elemento essencial para as plantas, sendo encontrado em baixa quantidade nos solos brasileiros. As concentrações de P no solo são da ordem de $2 \mu \mathrm{M}$, enquanto, nos teci-

\section{RESUMO}

O fósforo é considerado elemento essencial para as plantas e encontrado em baixa quantidade nos solos brasileiros. A torta de filtro, resíduo composto da mistura de bagaço moído e lodo da decantação, apresenta altos teores de matéria orgânica, fósforo e cálcio. O fósforo existente na torta de filtro é orgânico, sendo que a liberação do mesmo e do nitrogênio se dão gradativamente, por mineralização e por ataque de microorganismos no solo. O trabalho teve por objetivo avaliar o crescimento vegetativo e a produtividade da cana-de-açúcar, em função da adubação com torta de filtro enriquecida com fosfato solúvel. O experimento foi conduzido a campo, em Presidente Prudente (SP). Adotou-se o delineamento experimental em blocos completos ao acaso, no esquema fatorial $5 \times 4$, onde o primeiro fator constou de níveis de torta de filtro $\left(0 \mathrm{t} \mathrm{ha}^{-1} ; 0,5 \mathrm{t} \mathrm{ha}^{-1}\right.$; $1,0 \mathrm{tha}^{-1} ; 2,0 \mathrm{tha}^{-1}$; e 4,0 tha-1) e o segundo de níveis de fósforo $\left(0 \mathrm{~kg} \mathrm{ha}^{-1}, 50 \mathrm{~kg} \mathrm{ha}^{-1}, 100 \mathrm{~kg} \mathrm{ha}^{-1}\right.$ e $200 \mathrm{~kg} \mathrm{ha}^{-1}$ de $\left.\mathrm{P}_{2} \mathrm{O}_{5}\right)$, com 4 repetições, totalizando 80 parcelas. Os parâmetros avaliados foram o número de perfilhos, aos 30, 60, 90 e 120 dias após o plantio, ${ }^{\circ}$ Brix e produtividade. A produtividade de colmos e o perfilhamento foram influenciados pelas doses de torta de filtro aplicadas ao solo. As doses de torta de filtro e suas combinações com o fosfato não alteraram a qualidade do caldo (Brix), por ocasião da colheita.

PALAVRAS-CHAVE: Saccharum spp.; adubação organomineral; superfosfato triplo.

dos vegetais, estes valores são de, aproximadamente, $10 \mu \mathrm{M}$ (Mimura et al. 1999). A presença do fósforo é necessária para a síntese de compostos fosforilados e a falta deste nutriente causa distúrbios imediatos no metabolismo e no desenvolvimento das plantas (Cezar et al. 1987).

Além da baixa disponibilidade de $\mathrm{P}$, os solos altamente intemperizados apresentam baixa capacidade de troca catiônica (CTC) e elevada adsorção aniônica,

1. Trabalho recebido em set./2009 e aceito para publicação em nov./2010 (nº registro: PAT 7272/ DOI: 10.5216/pat.v40i4.7272).

2. Universidade Estadual Paulista, Faculdade de Ciências Agronômicas, Departamento de Produção Vegetal, Botucatu, SP, Brasil. E-mail: diego@fca.unesp.br.

3. Universidade do Oeste Paulista, Centro de Ciências Agrárias, Departamento de Produção Vegetal, Presidente Prudente, SP, Brasil.E-mails: tiritan@unoeste.br, lutti6@hotmail.com.

3. Instituto Agronômico do Paraná, Departamento de Fitotecnia, Londrina, PR, Brasil. E-mail: sfoloni@iapar.br. 
condições que proporcionam elevada retenção de ânions, como o fosfato, o sulfato e o molibdato, e baixa disponibilidade de bases. Assim, à medida que o intemperismo avança, os solos passam de fonte para dreno de fósforo inorgânico (Pi) (Novais \& Smyth 1999). Segundo Loganathan \& Fernando (1980), quando se aplica uma fonte solúvel de fósforo a determinado solo, mais de $90 \%$ do total aplicado já é adsorvido na primeira hora de contato com o solo. Novais (1980) também relata que o maior tempo de contato solo-fosfato causa sua maior solubilidade, ocasionando menor disponibilidade de fósforo para as plantas. A deficiência de $\mathrm{P}$ é problemática, pois reduz a absorção de N, como demonstrado em diversos trabalhos (Miller 1974, Lee 1982, Rufty et al. 1993, Magalhães 1996, Schjorring 1996, Novais \& Smyth 1999).

Além dos benefícios no campo, a adubação fosfatada também é de grande importância na qualidade da cana-de-açúcar, essencial em unidades industriais. Segundo Korndorfer (2004), a presença de fósforo no caldo exerce papel fundamental no processo de clarificação. Caldos contendo baixos teores de $\mathrm{P}_{2} \mathrm{O}_{5}$ são de difícil floculação e, neste caso, a decantação das impurezas (bagacilho, argila, clorofila, etc.) é dificultada. Caldo turvo e de coloração intensa implica na produção de açúcar de pior qualidade e, portanto, de menor valor comercial.

Uma alternativa para se aumentar a disponibilidade de $\mathrm{P}$, em áreas cultivadas com cana-de-açúcar, é a aplicação de fertilizantes fosfatados, em mistura com resíduos orgânicos. Para aumentar a eficiência da adubação fosfatada, em lavouras de cana-de-açúcar, com a consequente redução das doses empregadas, principalmente em áreas que vêm sendo cultivadas com a gramínea por um longo período, Bittencourt et al. (2006) recomendam utilizar um carregador orgânico, como a torta de filtro, para aumentar a massa e proteger o fósforo da fixação.

A torta de filtro é um resíduo composto da mistura de bagaço moído e lodo da decantação, sendo proveniente do processo de clarificação do açúcar. Para cada tonelada de cana moída, são produzidos de $30 \mathrm{~kg}$ a $40 \mathrm{~kg}$ de torta. É um composto orgânico rico em cálcio, nitrogênio e potássio, com composição variável, dependendo da variedade da cana e da sua maturação.

Nunes Júnior (2008) relata que a torta de filtro é um excelente produto orgânico para a recuperação de solos exauridos ou de baixa fertilidade, que sai da filtragem com $75-80 \%$ de umidade, e que sua compo- sição química média apresenta altos teores de matéria orgânica e fósforo, sendo, também, rica em nitrogênio e cálcio, além de teores consideráveis de potássio, magnésio e micronutrientes. O fósforo existente na torta de filtro é orgânico, sendo que a liberação do mesmo e do nitrogênio se dão gradativamente, por mineralização e por ataque de micro-organismos no solo. O cálcio, que aparece em grande quantidade, é resultado da chamada caleação do caldo, durante o processo de tratamento do mesmo, para a fabricação de açúcar. Já o fósforo é adicionado juntamente com os produtos auxiliares utilizados para floculação das impurezas do caldo.

Ferreira et al. (1986) apresentam a composição média da torta de filtro expressa em \% da matéria seca, sendo 77 a 85 de matéria orgânica; 1,1 a 1,4 de $\mathrm{N} ; 1,04$ a 2,55 de $\mathrm{P}_{2} \mathrm{O}_{5} ; 0,3$ a 0,96 de $\mathrm{K}_{2} \mathrm{O} ; 4,07$ a 5,46 de $\mathrm{CaO} ; 0,15$ a 0,56 de $\mathrm{MgO}$; e 2,70 a 2,96 de $\mathrm{SO}_{3}$. Nunes Júnior (2008) completa esta composição média apresentada, mostrando que a torta de filtro também é rica em micronutrientes: $0,8-1,2 \%$ de ferro, 500 $800 \mathrm{mg} \mathrm{kg}^{-1}$ de manganês, $40-80 \mathrm{mg} \mathrm{kg}^{-1}$ de cobre e $150-220 \mathrm{mg} \mathrm{kg}^{-1}$ de zinco.

O modo de aplicação do produto é testado de diferentes formas, nas unidades de produção, desde a aplicação da área total, até nas entrelinhas, ou nos sulcos de plantio (Cortez et al. 1992). Segundo Penso et al. (1982), uma das formas para seu aproveitamento é a aplicação conjunta com fosfatos naturais, uma vez que a torta de filtro pode melhorar a solubilidade destes compostos, disponibilizando, mais rapidamente, o fósforo e reduzindo sua fixação, quando comparado com a aplicação do nutriente sem a torta. Segundo Korndorfer \& Anderson (1997), a torta de filtro promove alterações significativas nos atributos químicos do solo, tais como aumento na disponibilidade de fósforo, cálcio e nitrogênio, aumento nos teores de carbono orgânico e capacidade de troca de cátions e, ainda, diminuição nos teores de alumínio trocáveis.

A torta de filtro, segundo Rossetto \& Dias (2005), quando incorporada ao solo, em doses elevadas, apresenta propriedades corretivas da acidez do solo, devido aos efeitos quelantes da matéria orgânica sobre o alumínio. Por ser um material orgânico, a torta de filtro mostra elevada capacidade de retenção de água a baixas tensões e esta propriedade contribui tanto para aumentar a produtividade da cana-de-açúcar, especialmente em regime não irrigado, como para assegurar melhor brotação em plantios realizados em épocas desfavoráveis. 
Neste contexto, objetivou-se, com este trabalho, avaliar o crescimento vegetativo e a produtividade da cana-de-açúcar, em função da adubação com torta de filtro enriquecida com fosfato solúvel (superfosfato triplo), no fundo do sulco de plantio.

\section{MATERIAL E MÉTODOS}

O experimento foi conduzido a campo, em área experimental da Faculdade de Agronomia da Universidade do Oeste Paulista (Unoeste), localizada no município de Presidente Prudente, SP (22 07'30”S, $51^{\circ} 26^{\prime} 00^{\prime \prime} \mathrm{W}$ e $433 \mathrm{~m}$ de altitude), durante os meses de novembro de 2007 a agosto de 2008. O clima da região, segundo a classificação de Köppen, é do tipo Cwa, ou seja, tropical, com estação chuvosa e quente bem definida, entre os meses de setembro e março, e inverno seco, com temperaturas amenas, entre os meses de abril e setembro.

O solo foi caracterizado, segundo Embrapa (2006), como Latossolo Vermelho distrófico, com relevo suave, ondulado e boa drenagem. Foram coletadas amostras para caracterização de atributos químicos (Raij et al. 2001) e granulometria (Embrapa 1999), na camada 0-20 cm, com os seguintes resultados: $\mathrm{pH}\left(\mathrm{CaCl}_{2} 1 \mathrm{~mol} \mathrm{~L}^{-1}\right) 5,9 ; 18 \mathrm{~g} \mathrm{dm}^{-3}$ de $\mathrm{MO} ; 16 \mathrm{mg} \mathrm{dm}^{-3}$ de $\mathrm{P}_{\text {resina }} ; 27 \mathrm{mmol}_{\mathrm{c}} \mathrm{dm}^{-3} \mathrm{de}$ $\mathrm{H}+\mathrm{Al} ; 1,2 \mathrm{mmol}_{\mathrm{c}} \mathrm{dm}^{-3} \mathrm{de} \mathrm{K} ; 38 \mathrm{mmol}_{\mathrm{c}}^{\mathrm{c}} \mathrm{dm}^{-3} \mathrm{de}$ $\mathrm{Ca} ; 12 \mathrm{mmol}_{\mathrm{c}} \mathrm{dm}^{-3} \mathrm{de} \mathrm{Mg} ; 52 \mathrm{mmol}_{\mathrm{c}} \mathrm{dm}^{\mathrm{c}}$ de SB; $69 \mathrm{mmol}_{\mathrm{c}} \mathrm{dm}^{-3}$ de CTC; 74\% de saturação por bases (V); $62 \%$ de saturação por alumínio (m); $740 \mathrm{~g} \mathrm{~kg}^{-1}$ de areia; $80 \mathrm{~g} \mathrm{~kg}^{-1}$ de silte; e $180 \mathrm{~g} \mathrm{~kg}^{-1}$ de argila.

A variedade de cana-de-açúcar (Saccharum officinarum L.) escolhida para a realização do experimento foi a RB86-7515, em função da recomendação regional. A torta de filtro foi obtida junto à Destilaria Alvorada do Oeste, no município de Santo Anastácio (SP), no dia 8 de novembro, com $34,85 \%$ de massa seca, segundo as análises de umidade realizadas pelo Laboratório de Tecidos Vegetais da Unoeste. Em seguida, a torta de filtro foi seca ao ar livre, durante seis dias, até atingir $80 \%$ de massa seca.

A análise da torta de filtro utilizada no experimento foi realizada pelo Laboratório de Solos da Unoeste e apresentou os seguintes valores, expressos na matéria seca: $\mathrm{pH}\left(\mathrm{CaCl}_{2} 1 \mathrm{~mol} \mathrm{~L}^{-1}\right) 5,4$; umidade perdida a $65^{\circ} \mathrm{C}$ de 70,7\%; 57,25\% de MO; 9,5 $\mathrm{g} \mathrm{kg}^{-1}$ de N; $3,3 \mathrm{~g} \mathrm{~kg}^{-1}$ de P; 4,6 $\mathrm{g} \mathrm{kg}^{-1}$ de K; 9, $1 \mathrm{~g} \mathrm{~kg}^{-1} \mathrm{de} \mathrm{Ca} ; 2,5 \mathrm{~g} \mathrm{~kg}^{-1} \mathrm{de} \mathrm{Mg}$; $7,2 \mathrm{~g} \mathrm{~kg}^{-1}$ de S; $124 \mathrm{mg} \mathrm{kg}^{-1}$ de Cu; $758 \mathrm{mg} \mathrm{kg}^{-1}$ de Mn; $282 \mathrm{mg} \mathrm{kg}^{-1}$ de Zn; e $23808 \mathrm{mg} \mathrm{kg}^{-1}$ de Fe.
Foi realizado o preparo convencional do solo, com aragem e gradagem, antes do plantio. A adubação mínima de plantio foi realizada de acordo com Raij et al. (1997), sendo composta por $30 \mathrm{~kg} \mathrm{ha}^{-1}$ de $\mathrm{N}$ (66,7 $\mathrm{kg} \mathrm{ha}^{-1}$ de ureia), $100 \mathrm{~kg} \mathrm{ha}^{-1} \mathrm{de} \mathrm{K}_{2} \mathrm{O}$ (166 kg ha-1 de cloreto de potássio), variando apenas as doses de $\mathrm{P}$, e torta de filtro, segundo o delineamento experimental.

Cada parcela experimental constou de 5 linhas de 5 metros de comprimento, espaçadas em 1,5 m. Adotou-se o delineamento experimental em blocos completos ao acaso, no esquema fatorial $5 \times 4$, onde o primeiro fator constou de níveis de torta de filtro $\left(0 \mathrm{t} \mathrm{ha}^{-1} ; 0,5 \mathrm{t} \mathrm{ha}^{-1} ; 1,0 \mathrm{t} \mathrm{ha}^{-1} ; 2,0 \mathrm{t} \mathrm{ha}^{-1} ; \mathrm{e} 4,0 \mathrm{t} \mathrm{ha}^{-1}\right) \mathrm{e}$ o segundo de níveis de fósforo $\left(0 \mathrm{~kg} \mathrm{ha}^{-1}, 50 \mathrm{~kg} \mathrm{ha}^{-1}\right.$, $100 \mathrm{~kg} \mathrm{ha}^{-1}$ e $200 \mathrm{~kg} \mathrm{ha}^{-1}$ de $\mathrm{P}_{2} \mathrm{O}_{5}$ ), com 4 repetições, totalizando 80 parcelas.

No dia 14 de novembro de 2007, promoveu-se a sulcação da área experimental, à profundidade de $25-30 \mathrm{~cm}$. Dois dias após a sulcação, efetuaram-se as misturas dos adubos com a torta de filtro, segundo o delineamento experimental, com o auxílio de betoneira. Em seguida, realizou-se a distribuição uniforme das misturas, nos cinco sulcos de cada parcela. No dia 16 de novembro de 2007, realizou-se o plantio, de forma convencional, adotando-se o sistema de cana-de-ano. Na distribuição das mudas, utilizou-se a densidade média de 15 gemas por metro de sulco, por meio da distribuição de colmos "pé-com-ponta", e, em seguida, efetuou-se o corte manual dos colmos, em toletes de 3 gemas, sendo, posteriormente, cobertos com uma camada de solo. No dia 11 de janeiro de 2008, realizou-se cobertura nitrogenada com ureia $\left(50 \mathrm{~kg} \mathrm{ha}^{-1} \mathrm{de} \mathrm{N}\right)$, segundo recomendação de Raij et al. (1997).

As avaliações de produtividade foram realizadas nas 3 linhas centrais de cada parcela experimental. O primeiro parâmetro avaliado foi o número de perfilhos. Para isto, em 4 metros de cada linha central de plantio, foi contado o número de perfilhos, aos $30,60,90$ e 120 dias após o plantio. A contagem do número de perfilhos foi realizada até os 120 dias, período em que a cana-de-açúcar se encontra em fase de perfilhamento. A partir desta etapa, a competição entre os perfilhos pelos fatores de crescimento (luz, água, nutrientes e espaço) acentua-se, de modo que se constata a diminuição e paralisação deste processo (Segato et al. 2006).

Para a determinação do ${ }^{\circ}$ Brix, foi utilizado refratômetro de campo (marca TOKYO, modelo 032), que fornece diretamente a percentagem de sólidos 
solúveis do caldo da cana-de-açúcar. $\mathrm{O}^{\circ}$ Brix do meio do perfilho foi determinado tomando-se 5 perfilhos por parcela e os valores foram apresentados como média aritmética dos 5 perfilhos avaliados.

No dia 04 de novembro de 2008, realizou-se o corte manual, para avaliação dos componentes de produção determinantes para o potencial agrícola, sendo eles: 1) altura média do colmo, medido da base à inserção da folha +3 , amostrando-se cinco colmos seguidos em cada linha; 2) diâmetro médio dos colmos, estimado nos mesmos cinco colmos, mensurado no meio do internódio, à altura dada por um terço do comprimento do colmo; 3) peso dos colmos despontados; e 4) número de colmos, estimado com a contagem dos colmos de todas as linhas da parcela, de acordo com metodologia proposta por Landell (1995). Segundo o mesmo autor, considerando-se a densidade do colmo igual a 1 , o valor da produção de cana por hectare $(\mathrm{TCH})$ pode ser estimado pela seguinte fórmula: $\mathrm{TCH}=\left(\mathrm{d}^{2} \times \mathrm{C} \times \mathrm{h} \times 0,007854\right) / \mathrm{E}$, onde "d" é o diâmetro médio dos colmos $(\mathrm{cm})$, " $\mathrm{C}$ " o número de perfilhos por metro linear, " $h$ " a altura média dos colmos $(\mathrm{cm})$ e "E" o espaçamento entre os sulcos, neste caso, 1,5 metros.

Os dados obtidos foram submetidos a análise de variância, pelo teste $\mathrm{F}$, e, havendo significância, procedeu-se à análise de regressão dos fatores estudados.

\section{RESULTADOS E DISCUSSÃO}

Os resultados da análise de variância (Tabela 1) mostraram que, quanto à produtividade de colmos $(\mathrm{TCH})$, houve significância $(\mathrm{p}<0,05)$ de doses de torta de filtro aplicadas ao fundo do sulco de plantio, ou seja, a produtividade de colmos foi influenciada pelas doses de torta de filtro aplicadas ao solo (Tabela 1). Segundo Rossetto et al. (2008), o uso da torta de filtro, em canaviais, eleva a produtividade da cultura, por fornecer matéria orgânica, fósforo e cálcio, entre outros nutrientes. Completam, ainda, que o uso mais eficiente da torta de filtro é aplicá-la ao sulco de plantio, no qual o teor de água contido na torta favorece a brotação da cana e onde o $\mathrm{P}$, ao ser mineralizado, está próximo às raízes. Observou-se, ainda, significância a $1 \%$ de probabilidade, pelo teste $\mathrm{F}$, para a variável doses de fosfato, quando avaliou-se a produtividade de colmos (TCH). No entanto, não foi observado efeito significativo para a interação torta $\mathrm{x}$ fosfato (Tabela 1). Também, observou-se efeito significativo $(\mathrm{p}<0,05)$ das doses de torta de filtro para os valores de ${ }^{\circ}$ Brix. Já em relação às doses de fosfato e à interação torta x fosfato, não se observaram efeitos significativos (Tabela 1).

Quanto ao perfilhamento, observou-se efeito significativo, a $1 \%$ de probabilidade, para as variáveis doses de torta e dias após o plantio, e efeito significativo, a $5 \%$ de probabilidade, para a variável doses de fosfato. Para as variáveis torta $\mathrm{x}$ fosfato, torta $\mathrm{x}$ dias, fosfato $\mathrm{x}$ dias e torta $\mathrm{x}$ fosfato $\mathrm{x}$ dias, não foram encontrados efeitos significativos.

A análise de regressão revelou que a dose de 2,0 $\mathrm{t} \mathrm{ha}^{-1}$ de torta de filtro, associada aos diferentes níveis de fosfato, não influencia a produtividade de colmos (Figura 1a). Já as doses $0 \mathrm{t} \mathrm{ha}^{-1} ; 0,5 \mathrm{t} \mathrm{ha}^{-1}$; 1,0 $\mathrm{t} \mathrm{ha}^{-1}$; e 4,0 t ha ${ }^{-1}$ de torta de filtro apresentaram comportamento linear positivo, sendo as doses correspondentes a $1,0 \mathrm{tha}^{-1} \mathrm{e} 4,0 \mathrm{tha}^{-1}$ significativas a $1 \%$ e as doses $0 \mathrm{t} \mathrm{ha}^{-1}$ e $0,5 \mathrm{tha}^{-1}$ significativas a $5 \%$ de probabilidade.

Estes resultados positivos, em relação à produção de colmos, são devidos à matéria orgânica da torta de filtro possuir importante papel na melhoria da fertilidade do solo e nas suas propriedades físicas. Para Alleoni \& Beauclair (1995), a matéria orgânica de torta de filtro aumenta a capacidade de retenção de água, pois é higroscópica, chegando a reter água em

Tabela 1. Valores de F, calculados por meio de análises de variância, para a produtividade de colmos (TCH), ${ }^{\circ} \mathrm{Brix}$ do caldo na colheita e perfilhamento da lavoura de cana, aos 30, 60, 90 e 120 dias após o plantio (DAP), em razão de misturas de doses de fosfato solúvel com doses de torta de filtro, aplicadas nos sulcos de plantio (Presidente Prudente, SP, 2008).

\begin{tabular}{|c|c|c|c|}
\hline Causa da variação & $\mathrm{TCH}$ & Brix & Perfilhamento \\
\hline Doses de Torta & $2,72 *$ & $2,86^{*}$ & $18,94 * *$ \\
\hline Doses de Fosfato & $9,23 * *$ & $0,42 \mathrm{~ns}$ & $2,79 *$ \\
\hline Dias após o plantio & - & - & $539,10 * *$ \\
\hline Torta $\mathrm{x}$ Fosfato & $1,59 \mathrm{~ns}$ & $1,11 \mathrm{~ns}$ & $1,37 \mathrm{~ns}$ \\
\hline Torta x Dias & - & - & $1,29 \mathrm{~ns}$ \\
\hline Fosfato x Dias & - & - & $0,31 \mathrm{~ns}$ \\
\hline Torta x Fosfato x Dias & - & - & $0,24 \mathrm{~ns}$ \\
\hline $\mathrm{CV}(\%)$ & 16,86 & 3,06 & 19,62 \\
\hline
\end{tabular}



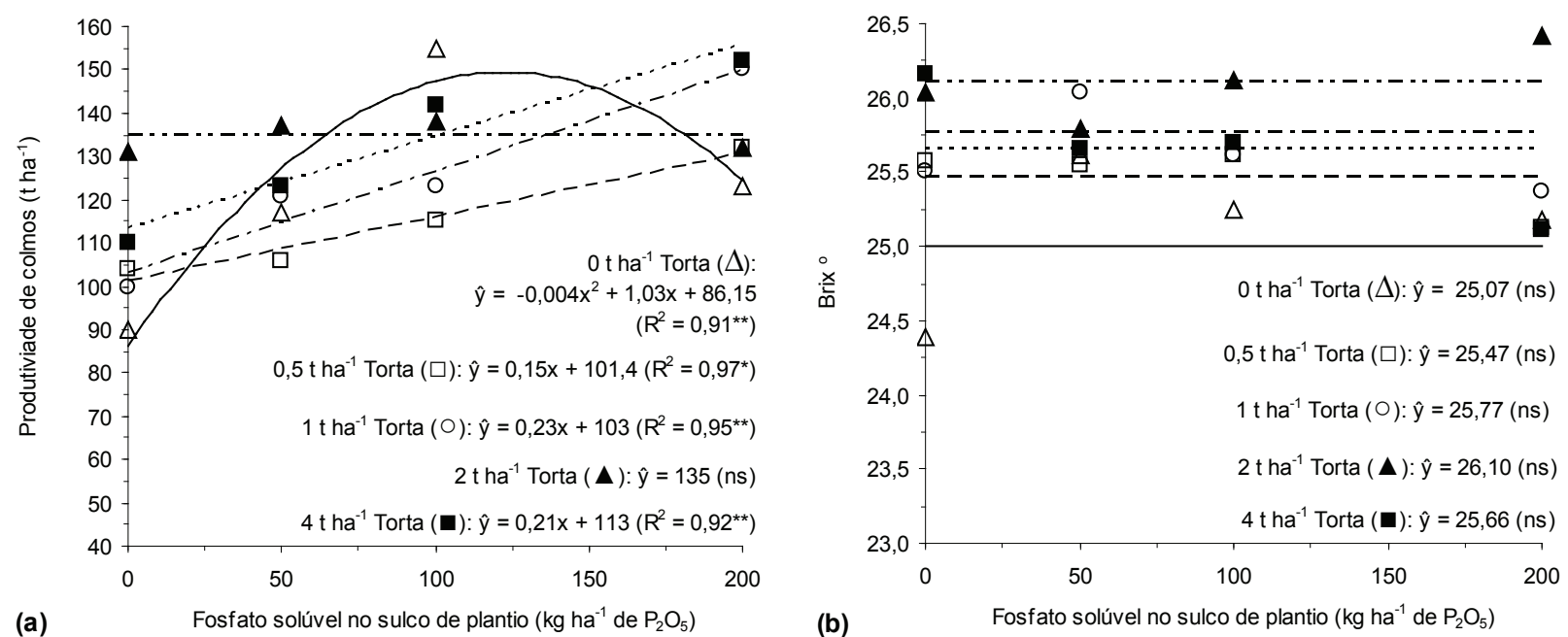

Figura 1. Produtividade de colmos (a) e ${ }^{\circ}$ Brix (b) do caldo, na colheita da cana-de-açúcar, em razão de doses de fosfato solúvel misturadas com $0 \mathrm{t} \mathrm{ha}^{-1}(\Delta) ; 0,5 \mathrm{tha}^{-1}(\square) ; 1,0 \mathrm{tha}^{-1}(0) ; 2,0 \mathrm{t} \mathrm{ha}^{-1}(\mathbf{\Delta})$; e 4,0 $\mathrm{t} \mathrm{ha}^{-1}(\mathbf{\square})$ de torta de filtro (base seca), aplicadas aos sulcos de plantio. * e**: significativos a $5 \%$ e $1 \%$ de probabilidade, respectivamente; ns: não significativo (Presidente Prudente, SP, 2008).

até seis vezes o seu próprio peso. Ainda, promove a redução da densidade aparente do solo e o aumento da porosidade total do solo; forma agregados capazes de reduzir a erosão e aumentar a capacidade de absorção do solo; e aumenta a capacidade de troca catiônica, pela ação de micelas húmicas coloidais, com atividade superior às argilas. Aumenta, também, os teores de nitrogênio, fósforo e enxofre, a partir da decomposição e da mineralização da matéria orgânica, e promove a redução da fixação do fósforo pelos óxidos de ferro e alumínio, bloqueando os sítios de fixação com os radicais orgânicos.

No caso em que a dose de $2,0 \mathrm{t} \mathrm{ha}^{-1}$ de torta de filtro, associada aos diferentes níveis de fosfato, não influenciou a produtividade de colmos (Figura 1a), é preciso destacar que, mesmo na ausência de fosfato, a produtividade foi, estatisticamente, igual à dose máxima de fosfato testada, sendo uma produtividade elevada de, aproximadamente, $135 \mathrm{t}_{\text {cana }} \mathrm{ha}^{-1}$, provavelmente decorrente do elevado teor de P presente no solo. Resultados semelhantes são descritos por Garcia (2005), que testou fonte orgânica de adubo isoladamente e associado a doses de fósforo solúvel. Os resultados deste autor mostram que as fontes orgânicas de fósforo, aplicadas isoladamente, proporcionaram média semelhante de rendimento, quando associadas ao adubo mineral, e, ainda, quando da aplicação do adubo mineral isoladamente. Já a dose de 4 ton ha ${ }^{-1}$ de torta de filtro, associada aos diferentes níveis de fosfato, apresentou resposta significativa, ou seja, influencia a produtividade de colmos. Tal resposta à adição de matéria orgânica (torta de filtro), na presença de adubo mineral fosfatado, sobre a produtividade de colmos, ajustou-se ao modelo linear. Provavelmente, os efeitos positivos da torta de filtro sobre a produtividade de colmos resultam não somente do suprimento de nutrientes, mas, também, da elevação no acúmulo de umidade no solo e aumento na capacidade de troca de cátions, ocasionando, assim, melhoria no aproveitamento dos nutrientes originalmente presentes no solo.

Interações significativas com $\mathrm{N}$ e $\mathrm{P}$, no aumento da produção, levaram Prasad (1976) a concluir ser desnecessário o uso de $\mathrm{P}$, quando se aplica torta de filtro ao sulco de plantio, porém, este autor trabalhou com altas doses de torta de filtro, sendo estes resultados citados obtidos nos tratamentos que receberam doses iguais ou superiores a $20 \mathrm{t} \mathrm{ha}^{-1}$. No entanto, a hipótese do trabalho não é substituir a adubação fosfatada e sim melhorar sua eficiência. As fontes de fósforo solúvel perdem eficiência, ao longo do tempo, pois ocorre adsorção ou fixação deste elemento pelo solo (Kondorfer et al. 1989). O uso de torta de filtro representa grande reciclagem de nutrientes e de matéria orgânica. Neste momento de alta no preço dos fertilizantes, a utilização deste resíduo significa melhor aproveitamento e economia no uso do fósforo.

Em relação aos valores de ${ }^{\circ}$ Brix, a Figura $1 b$ revela que as doses de torta de filtro não apresentam efeito significativo sobre o Brix, independentemente 
dos níveis de fosfato associados a estas doses de torta. Este resultado está de acordo com Cantarella et al. (2002), que, ao avaliarem misturas, em diferentes proporções de fosfato natural reativo e fosfato solúvel em água para a cana-de-açúcar, concluíram não haver efeitos no acúmulo de açúcar pela planta. Já Vijav \& Verma (2001), ao estudarem o efeito isolado ou combinado de adubos orgânicos e minerais, notaram que a adubação mineral, associada à orgânica, promoveu aumentos significativos no teor de açúcar presente no caldo da cana. Os resultados obtidos por Nema et al. (1995), na Índia, que trabalharam com torta de filtro associada com a adubação mineral, apresentam diminuição no teor de açúcar presente no caldo da cana, quando da aplicação da adubação mineral isolada, e aumentos nos valores, quando foram usadas adubações orgânicas associadas ou não à adubação química.
A figura 2 apresenta o gráfico de regressão do perfilhamento da cana-de-açúcar, aos 30, 60, 90 e 120 dias após o plantio da lavoura (DAP), em razão de doses de torta de filtro aplicadas aos sulcos de plantio, em misturas com $0 \mathrm{~kg} \mathrm{ha}^{-1}$ (a), $50 \mathrm{~kg} \mathrm{ha}^{-1}$ (b), $100 \mathrm{~kg} \mathrm{ha}^{-1}$ (c) e $200 \mathrm{~kg} \mathrm{ha}^{-1}$ (d) de $\mathrm{P}_{2} \mathrm{O}_{5}$ solúvel. Observou-se, pela análise de regressão, que a dose $0 \mathrm{~kg} \mathrm{ha}^{-1}$ de $\mathrm{P}_{2} \mathrm{O}_{5}$ não apresentou efeito significativo no perfilhamento da cana, nos primeiros 30 dias. Já aos 60, 90 e 120 dias após o plantio (DAP), as variáveis apresentaram comportamento linear positivo, apontando que houve efeito significativo a $5 \%$, aos 60 DAP, e a $1 \%$, aos 90 e 120 DAP. O mesmo comportamento foi observado para a dose de $50 \mathrm{~kg} \mathrm{ha}^{-1} \mathrm{de}$ $\mathrm{P}_{2} \mathrm{O}_{5}$, na qual, aos 30 DAP, não foi observado efeito significativo e, aos 60, 90 e 120 DAP, observou-se efeito significativo a $1 \%$. Em relação à dose de

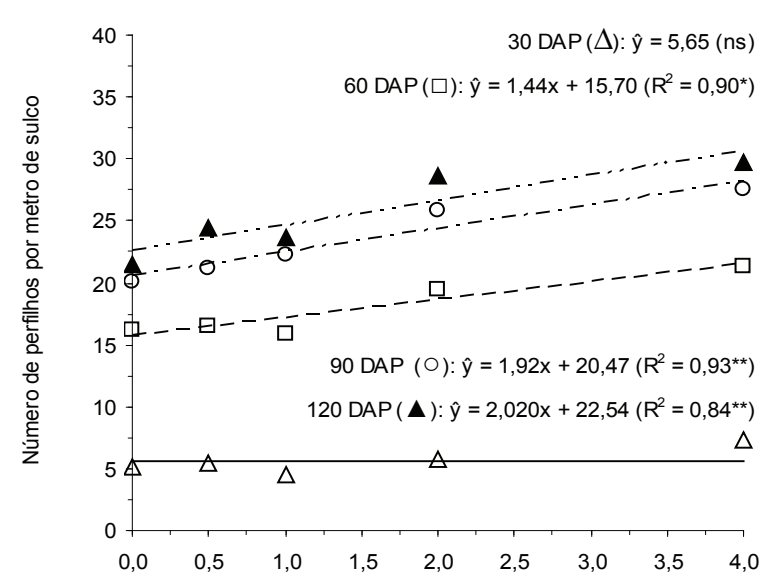

(a)

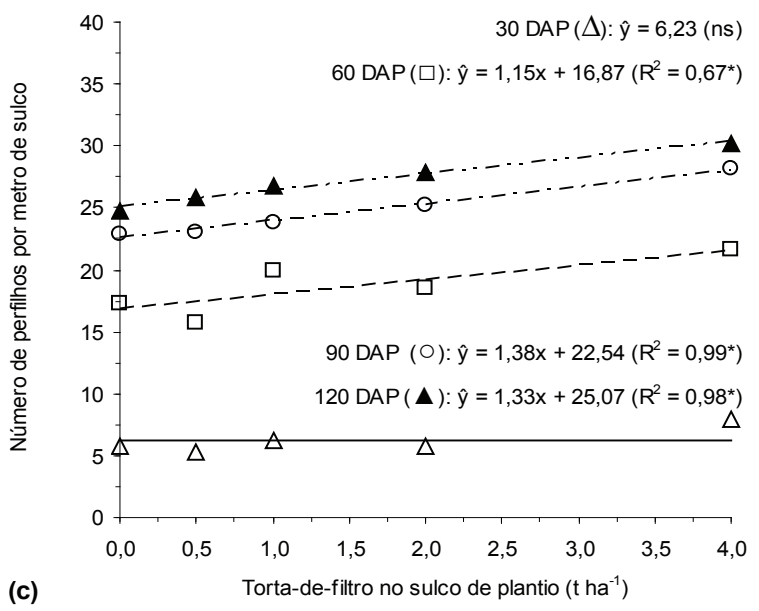

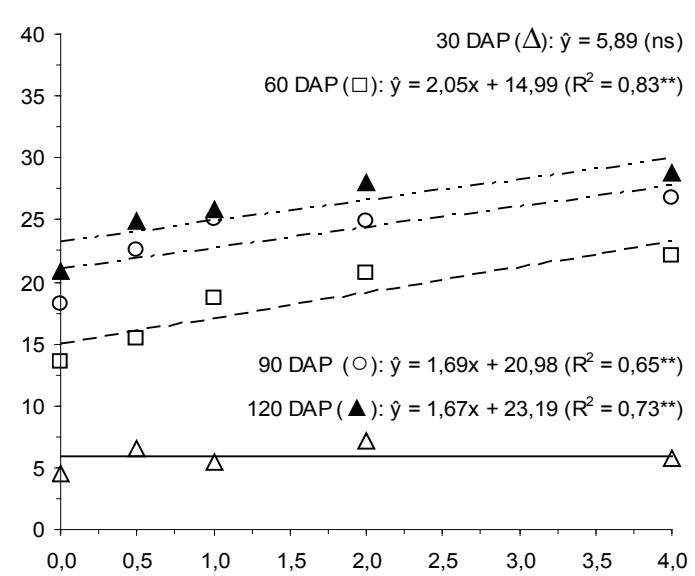

(b)

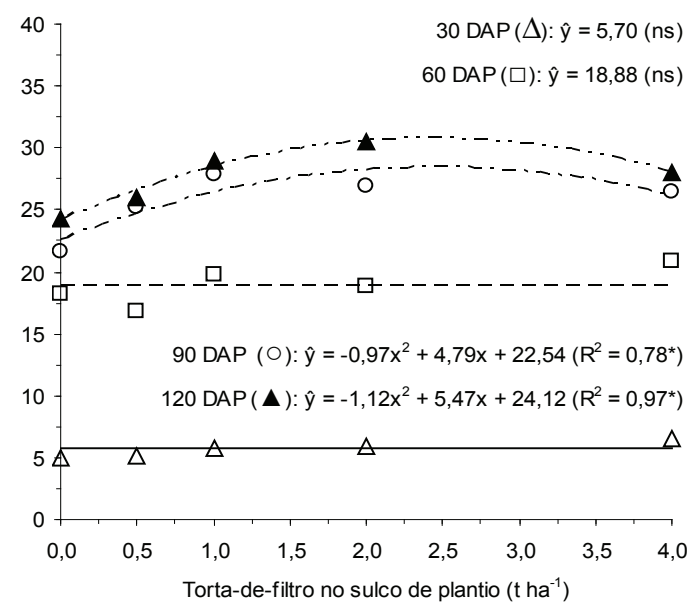

Figura 2. Perfilhamento da cana-de-açúcar, aos $30(\Delta), 60(\square), 90(\circ)$ e $120(\boldsymbol{\Delta})$ dias após o plantio da lavoura (DAP), em razão de doses de torta de filtro aplicadas aos sulcos de plantio, em misturas com $0 \mathrm{~kg} \mathrm{ha}^{-1}$ (a), $50 \mathrm{~kg} \mathrm{ha}^{-1}$ (b), $100 \mathrm{~kg} \mathrm{ha}{ }^{-1}$ (c) e $200 \mathrm{~kg} \mathrm{ha}^{-1}$ (d) de $\mathrm{P}_{2} \mathrm{O}_{5}$ solúvel. * e **: significativos a 5\% e 1\% de probabilidade, respectivamente; ns: não significativo (Presidente Prudente, SP, 2008). 
$100 \mathrm{~kg} \mathrm{ha}^{-1}$ de $\mathrm{P}_{2} \mathrm{O}_{5}$, tem-se o mesmo comportamento, sem efeito significativo no perfilhamento, aos 30 DAP, e com efeito significativo a $5 \%$, aos 60,90 e 120 DAP. Já para a dose de $200 \mathrm{~kg} \mathrm{ha}^{-1} \mathrm{de}_{2} \mathrm{O}_{5}$, não foi observado efeito significativo aos 30 e 60 DAP. Aos 90 e 120 DAP, as variáveis apresentaram comportamento quadrático, com diferença estatística entre os tratamentos de menores e maiores doses de torta de filtro, estando os melhores resultados associados às maiores doses, até o nível de 2,0 t ha $^{-1}$, iniciando, posteriormente, um decréscimo, sendo que os tratamentos que receberam doses de torta de filtro equivalentes a 4,0 t ha ${ }^{-1}$ não apresentaram maior perfilhamento, quando comparados aos que receberam 2,0 $\mathrm{t} \mathrm{ha}^{-1}$. As maiores doses podem não ter apresentado os melhores resultados, devido ao elevado teor de $\mathrm{P}$ no solo.

Cabe ressaltar que a liberação do fósforo presente na torta de filtro para o solo é gradativa, proporcionando residual médio de 2 a 3 cortes, dependendo do clima da localidade (Santos 2009). Segundo Nunes Júnior (2008), nos climas tropicais, a torta de filtro apresenta residual por 2 anos e, nos climas mais amenos, como o dos Estados de São Paulo e Paraná, a torta de filtro pode agir por 3 anos.

Os resultados positivos de produtividade já eram esperados, uma vez que a utilização da torta de filtro, associada ao fertilizante fosfatado, vem sendo adotada como prática em algumas usinas, sendo os resultados positivos atribuídos ao fato de que radicais orgânicos na torta de filtro em decomposição podem ocupar sítios de fixação de fósforo (Rossetto et al. 2008), protegendo este nutriente da reação com os minerais de argila e óxidos de ferro.

Ferreira et al. (1986) trabalharam com dados médios de quatro usinas, na safra de 1985 , com cana-planta, e também encontraram resultados positivos com o uso da torta de filtro. Os autores compararam o tratamento sem adição de torta de filtro $\left(25 \mathrm{~kg} \mathrm{ha}^{-1}\right.$ de $\mathrm{N}, 125 \mathrm{~kg} \mathrm{ha}^{-1}$ de $\mathrm{P}_{2} \mathrm{O}_{5}$ e $125 \mathrm{~kg} \mathrm{ha}^{-1}$ de $\mathrm{K}_{2} \mathrm{O}$ ) com o tratamento com $5 \mathrm{t} \mathrm{ha}^{-1}$ de matéria seca de torta de filtro ( $0 \mathrm{~kg} \mathrm{ha}^{-1} \mathrm{de} \mathrm{N}, 48 \mathrm{~kg} \mathrm{ha}^{-1} \mathrm{de}_{2} \mathrm{O}_{5}$ e $80 \mathrm{~kg} \mathrm{ha}^{-1} \mathrm{de}$ $\mathrm{K}_{2} \mathrm{O}$ ). $\mathrm{O}$ primeiro tratamento apresentou produtividade média de 99,8 toneladas de cana por hectare (TCH), enquanto, no segundo, apesar da redução da adubação fosfatada e potássica e da isenção do $\mathrm{N}$, a produtividade obtida foi de 108,5 TCH, diferença de 8,7 TCH, devido à utilização da torta de filtro. Em cana soca, Ferreira et al. (1986) testaram a aplicação de $0 t^{\text {ha }}{ }^{-1}$, $5 \mathrm{t} \mathrm{ha}^{-1}$ e $10 \mathrm{t} \mathrm{ha}^{-1}$ de torta de filtro, sem aplicação de $\mathrm{N}$ e K. A produtividade média, nos tratamentos que receberam $0 \mathrm{t} \mathrm{ha}^{-1}$ de torta de filtro, foi de $61,3 \mathrm{TCH}$; $71,6 \mathrm{TCH}$, para $5 \mathrm{t} \mathrm{ha}^{-1}$; e 70,0 TCH, para $10 \mathrm{t} \mathrm{ha}^{-1}$.

\section{CONCLUSÃO}

A produtividade de colmos ( $\mathrm{TCH})$ e o perfilhamento foram influenciados pelas doses de torta de filtro aplicadas ao solo. As doses de torta de filtro e suas combinações com o fosfato não alteraram a qualidade do caldo da cana, ao se avaliar o Brix do caldo, por ocasião da colheita.

\section{REFERÊNCIAS}

ALLEONI, L. R. F.; BEAUCLAIR, E. G. F. Cana-deaçúcar cultivada após milho e amendoim, com diferentes doses de adubo. Scientia Agricola, Piracicaba, v. 52, n. 3 , p. 409-415, 1995.

BITTENCOURT, V. C. et al. Torta de filtro enriquecida. Idea News, Ribeirão Preto, v. 6, n. 63, p. 2-6, 2006.

CANTARELLA, H. et al. Mistura em diferentes proporções de fosfato reativo natural e fosfato solúvel em água para a cana-de-açúcar. In: CONGRESSO NACIONAL DA SOCIEDADE DOS TÉCNICOS AÇUCAREIROS E ALCOOLEIROS DO BRASIL, 8., 2002, Recife. Anais.. Recife: STAB, 2002. p. 218-224.

CEZAR, M. A. A. et al. Capacidade de fosfatos naturais e artificiais em elevar o teor de fósforo no caldo de canade-açúcar (cana-planta), visando o processo industrial. STAB: Açúcar, Álcool e Subprodutos, Piracicaba, v. 5, n. 5, p. 32-38, 1987.

CORTEZ, L.; MAGALHÃES, P.; HAPP, J. Principais subprodutos da agroindústria canavieira e sua valorização. Revista Brasileira de Energia, Campinas, v. 2, n. 2, p. 111146, 1992.

EMPRESA BRASILEIRA DE PESQUISA AGROPECUÁRIA (Embrapa). Centro Nacional de Pesquisa de Solos. Sistema brasileiro de classificação de solos. Rio de Janeiro: Embrapa, 1999.

EMPRESA BRASILEIRA DE PESQUISA AGROPECUÁRIA (Embrapa). Tecnologia de produção de soja: região central do Brasil - 2007. Londrina: Embrapa Soja, 2006.

FERREIRA, E. S.; ZOTARELLI, E. M. M.; SALVIATI, L. Efeitos da utilização da torta de filtro na produtividade da cana-de-açúcar. In: SEMINÁRIO DE TECNOLOGIA AGRONÔMICA, 4., 1986, Piracicaba. Anais... Piracicaba: Copersucar, 1986. p. 321-331. 
GARCIA, J. C. Efeitos da adubação orgânica, associada ou não à adubação química, calagem e fosfatagem, nos rendimentos agrícola e de aguardente teórica da cana-deaçúcar (Saccharum spp). 2005. 82 f. Tese (Doutorado em Fitotecnia)-Universidade Federal de Lavras, Lavras, 2005.

KORNDORFER, G. H. Fósforo na cultura da cana-deaçúcar. In: YAMADA, T.; ABDALLA, S. R. S. (Eds.). Fósforo na agricultura brasileira. Piracicaba: Associação Brasileira para Pesquisa da Potassa e do Fosfato, 2004. p. 290-306.

KORNDORFER, G. H.; ANDERSON, D. L. Use and impact of sugar-alcohol residues vinasse and filter cake on sugarcane production in Brazil. Sugar y Azucar, Englewood Cliffs, v. 92, n. 3, p. 26-35, 1997.

KORNDORFER, G. H. et al. Resposta da cana planta a diferentes fontes de fósforo. Boletim Técnico Copersucar, São Paulo, v. 45, n. 1, p. 31-37, 1989.

LANDELL, M. G. de A. Método experimental: ensaios de competição em cana-de-açúcar. In: MARTINS , A. L. M.; LANDELL, M. G. de A. Conceitos e critérios para avaliação experimental em cana-de-açúcar utilizados no Programa Cana IAC. Pindorama: Instituto Agronômico, 1995. p. 2-14.

LEE, R. B. Selectivity and kinetics of ion uptake by barley plants following nutrient deficiency. Annals of Bottany, Oxford, v. 50, n. 4, p. 429-449, 1982.

LOGANATHAN, P.; FERNANDO, W. T. Phosphorus sorption by some coconut growing acid soils of Sri Lanka and its relationship to selected soil properties. Journal of the Science of Food and Agriculture, Oxford, v. 31, n. 7, p. 709-717, 1980.

MAGAlHÃES, J. V. Absorção e translocação de nitrogênio por plantas de milho (Zea mays L.) submetidas a períodos crescentes de omissão de fósforo na solução nutritiva. 1996. 76 f. Dissertação (Mestrado em Solos e Nutrição de Plantas)-Universidade Federal de Viçosa, Viçosa, 1996.

MILLER, M. H. Effects of nitrogen on phosphorus absorption by plants. In: CARSON, E. W. (Ed.). The plant root and its environment. Charlottesville: University Press of Virginia, 1974. p. 634-668.

MIMURA, T. Regulation of phosphate transport and homeostasis in plant cells. International Review of Cytology, Amsterdam, v. 190, n. 2, p. 149-200, 1999.

NEMA, G. K.; VAIDYA, M. S.; BANGAR, K. S. Response of sugarcane to fertilizer nitrogen and organic manures in black calcareous soils of Madhya Pradesh. Journal of Soils and Crops, Madhya Pradesh, v. 5, n. 2, p. 129-132, 1995.

NOVAIS, R. F. Efeito do tempo de incubação do fosfato de araxá em solos sobre o fósforo disponível. Revista Brasileira de Ciências de Solo, Viçosa, v. 4, n. 1, p. 153155,1980 .
NOVAIS, R. F.; SMYTH, T. T. Fósforo em solo e planta em condições tropicais. Viçosa: UFV, 1999.

NUNES JÚNIOR, D. Torta de filtro: de resíduo a produto nobre. Idea News, Ribeirão Preto, v. 8, n. 92, p. 22-30, 2008.

PENSO, J. S. A.; BRAGA, J. M.; THIÉBAUT, J. T. L. Avaliação da solubilidade de fosfato de patos: III - mistura com torta de filtro e vinhaça. Revista Agronômica Ceres, Viçosa, v. 29, n. 165, p. 516-525, 1982.

PRASAD, M. Response of sugarcane to filter press mud and N, P and K fertilizers: I. Effect on sugarcane yield and sucrose content. Agronomy Journal, Madison, v. 68, n. 4, p. 539-543, 1976.

RAIJ, B. van et al. Análise química para avaliação da fertilidade de solos tropicais. Campinas: Instituto Agronômico, 2001.

RAIJ, B. van et al. (Eds.). Recomendações de adubação e calagem para o Estado de São Paulo. 2. ed. Campinas: IAC, 1997. (Boletim Técnico, 100).

ROSSETTO, R.; DIAS, F. L. F. Nutrição e adubação da cana-de-açúcar: indagações e reflexões. Informações Agronômicas, Piracicaba, n. 110, p. 6-11, 2005.

ROSSETTO, R.; DIAS, F. L. F.; VITTI, A. C. Problemas nutricionais dos solos nas novas fronteiras canavieiras. Idea News, Ribeirão Preto, v. 8, n. 94, p. 78-90, 2008.

RUFTY, T. W. et al. Phosphate regulation of nitrate assimilation in soybean. Journal of Experimental Botany, Oxford, v. 44, n. 5, p. 879-891, 1993.

SANTOS, D. H. Adubação fosfatada no plantio da cana-de-açúcar a partir de torta de filtro enriquecida com fosfato solúvel. 2009. 36 f. Dissertação (Mestrado em Produção Vegetal)-Universidade do Oeste Paulista, Presidente Prudente, 2009.

SCHJORRING, J. K. Nitrate and ammonium absortion by plants growing at a sufficient or insufficient level of phosphorus in nutrient solution. In: LAMERS, H. (Ed.). Fundamental ecological and agricultural aspects of nitrogen metabolism in higher plants. Dordrecht: Martinus Nijhoff, 1996. p. 53-58.

SEGATO, S. V.; MATTIUZ, C. F. M.; MOZAMBANI, A. E. Aspectos fenológicos da cana-de-açúcar. In: SEGATO, S. V. et al. Atualização em produção de cana-de-açúcar. Piracicaba: Livroceres, 2006. p. 19-36.

VIJAV, K.; VERMA, K. S. Effect of N, P, K, Zn fertilizers and organic manure on plant and ratoon crops of sugarcane and soil fertility under continous cropping. In: ANNUAL CONVENTION OF THE SUGAR TECHNOLOGY ASSOCIATION OF INDIA, 63., 2001, Jaipur. Abstracts... New Delhi: Sugar Technologists Association of India, 2001. p. 135. 